\title{
PENGENDALIAN PERSEDIAAN DAN PENJADWALAN PASOKAN BAHAN BAKU IMPOR DENGAN METODE ABC ANALYSIS DI PT UNILEVER INDONESIA, CIKARANG, JAWA BARAT
}

\author{
Happy Fauzi Afianti ${ }^{1}$, Hery Hamdi Azwir ${ }^{2}$
}

\author{
Program Studi Teknik Industri, Fakultas Teknik, President University \\ Jl. Ki Hajar Dewantara, Kota Jababeka, Cikarang, Bekasi - Indonesia 17550 \\ Email: ${ }^{1}$ happyfauziafianti@yahoo.co.id, ${ }^{2}$ hery.azwir@president.ac.id
}

\begin{abstract}
Inventory control becomes a very important activity in a company because the cost of inventory can reach about $20 \%$ to $40 \%$ of the total annual value. Inventory is a capital or company asset consist of raw materials, work in process and finished product. Currently, the value of inventory at PT Unilever Indonesia Savory Factory has exceeded the maximum target of the company but some raw materials have shortage or stock-out, meaning that the current inventory condition is inefficient because the company invests too much in inventory but the shortage of inventory for certain raw materials still occurs. This is the reason why it is necessary to improve inventory efficiency. Improvements were made by utilizing $A B C$ inventory analysis method and arranging and scheduling raw material supply as needed, then making priority scale of raw material improvement on $A B C$ inventory analysis based on class $A, B$ and $C$. The research was continued by rescheduling the tracking delivery and counting time frozen horizon which is the amount of time it takes raw materials during the distribution process or delivery process, so the frozen horizon is smaller than lead time. $B y$ performing fixed order interval on class $A$ and fixed order quantity raw materials for class $B$ and $C$ raw materials, the quantity of imported raw materials gradually adjust to the needs and the high value of the company's inventory can be reduced gradually as well. The end result is the risk of shortage can be reduced as much as $26 \%$, overstock can be reduced by $12 \%$ and in total overall value over value inventory can be decreased as much as $23 \%$.
\end{abstract}

Keywords: inventory, ABC inventory analysis, fixed order interval, fixed order quantity, frozen horizon

\begin{abstract}
ABSTRAK
Pengendalian inventory menjadi aktivitas yang sangat penting pada sebuah perusahaan karena biaya inventory dapat mencapai sekitar $20 \%$ hingga $40 \%$ dari total nilai tahunan. Persediaan merupakan modal atau aset perusahaan berupa raw materials, work in process, dan finished product. Saat ini, nilai inventory di PT Unilever Indonesia Savoury Factory sudah melebihi target maksimum perusahaan. Namun, beberapa bahan baku mengalami shortage atau stock-out, artinya kondisi inventory saat ini tidak efisien karena perusahaan menanamkan terlalu banyak dana dalam persediaan namun kekurangan persediaan untuk bahan baku tertentu tetap terjadi. Hal ini menjadi alasan mengapa perlu dilakukan perbaikan efisiensi inventory. Perbaikan dilakukan dengan memanfaatkan metode analisis ABC persediaan dan melakukan pengaturan dan penjadwalan pasokan bahan baku sesuai kebutuhan, kemudian membuat skala prioritas perbaikan bahan baku pada analisis ABC persediaan berdasarkan kelas A, B, dan C. Penelitian dilanjutkan dengan melakukan rescheduling dengan melakukan tracking delivery dan menghitung waktu frozen horizon yaitu jumlah waktu yang dibutuhkan bahan baku selama proses distribusi atau proses delivery, sehingga frozen horizon lebih kecil dari lead time. Dengan melakukan fixed order interval pada bahan baku kelas A dan fixed order quantity untuk bahan baku kelas B dan C, maka kuantitas bahan baku impor secara bertahap menyesuaikan dengan kebutuhan dan tingginya nilai inventory perusahaan dapat dikurangi secara bertahap pula. Hasil akhirnya adalah risiko shortage dapat dikurangi sebanyak $26 \%$, overstock dapat dikurangi sebesar $12 \%$, dan secara total keseluruhan value over value inventory dapat diturunkan sebanyak $23 \%$.
\end{abstract}

Kata kunci: inventory, analisis ABC persediaan, fixed order interval, fixed order quantity, frozen horizon 


\section{PENDAHULUAN}

Persediaan atau inventory merupakan modal atau aset perusahaan berupa bahan baku (raw materials), barang atau bahan dalam proses produksi (work in process), dan barang hasil produksi yang siap dipasarkan (finished product). Persediaan atau pengadaan dan penyimpanan barang di industri atau perusahaan membutuhkan biaya besar. Biaya penyimpanan ini setiap tahun umumnya mencapai 20-40\% dari harga barang [1]. Strategi atau manajemen inventory dengan sistem yang tepat sangat dibutuhkan agar biaya persediaan optimum atau dengan total biaya paling rendah.

Aspek persediaan pada industri, terutama manufaktur, berperan penting bagi kelancaran proses produksi di perusahaan. Jika persediaan tidak mencukupi, perusahaan akan dihadapkan pada risiko ketidakmampuan untuk memenuhi kebutuhan pelanggan yang mengakibatkan perusahaan kehilangan kesempatan untuk mendapatkan keuntungan yang lebih tinggi, karena dalam praktiknya, sering kali permintaan konsumen mengalami fluktuasi baik jumlah, jenis, dan frekuensinya. Perusahaan harus melakukan suatu kebijakan persediaan untuk mengantisipasi penggunaan barang yang tidak pasti.

Setiap proses produksi memerlukan berbagai macam barang yang diperlukan dalam keperluan operasionalnya. Barang-barang tersebut dapat diproduksi sendiri atau harus didatangkan dari pemasok (lokal dan impor). Begitupun dengan PT Unilever Indonesia yang bergerak dalam bidang manufaktur produk consumer goods atau fast moving consumer goods (FMCG). Produk yang dihasilkan PT Unilever Indonesia sangat beragam dan pemasalahan yang muncul dari aspek persediaan sangat kompleks. Penelitian difokuskan pada persediaan di pabrik kategori foods, yaitu produk margarin, bumbu masak, dan kecap manis.

Dalam memenuhi permintaan konsumen, perusahaan menerapkan sistem make to stock dengan target nilai inventory yang telah ditentukan dan tidak melebihi target maksimum perusahaan. Namun, ketika observasi dilakukan, nilai inventory ternyata telah melebihi target maksimum, sedangkan jumlah persediaan bahan baku impor di gudang tidak sesuai kebutuhan sehingga sering kali menumpuk dan mengakibatkan tingginya biaya persediaan. Selain itu, beberapa bahan baku impor juga mengalami stok kritis. Keadaan ini sangat tidak efisien dan merugikan perusahan. Untuk itu, perlu dibuat suatu rencana pemesanan dan pengendalian persediaan bahan baku impor yang sesuai dengan kebutuhan perusahaan karena nilai inventory yang tinggi merupakan kerugian bagi perusahaan. Demikian pula bila perusahaan tidak memiliki persediaan yang mencukupi, dapat mengakibatkan hilangnya kesempatan meraih keuntungan akibat terjadinya kekurangaan bahan baku [2].

Pembelian bahan baku dari pemasok negara lain (impor) memiliki kebijakan yang berbeda dengan pembelian bahan baku lokal. Proses pemesanan lebih kompleks, seperti keharusan adanya dokumen lengkap pembelian yang merupakan syarat utama dalam melakukan pembelian impor serta harus mendapatkan izin dan persetujuan dari pihak-pihak yang bersangkutan sehingga membutuhkan waktu yang lebih lama. Pengendalian persediaan bahan baku impor memiliki risiko yang lebih tinggi ketika terjadi perubahan yang tidak sesuai dengan rencana. Dengan demikian, sistem pengendalian persediaan harus dilakukan dengan tepat agar pembelian bahan baku impor dapat berjalan sesuai ketentuan.

Salah satu metode untuk melakukan manajemen sistem pengendalian persediaan adalah analisis $\mathrm{ABC}$. Metode ini dapat digunakan dalam memecahkan masalah penentuan titik optimum, baik jumlah pemesanan maupun order point. Analisis ABC sangat berguna dalam memfokuskan perhatian manajemen terhadap penentuan jenis barang yang paling penting dalam sistem inventory yang bersifat multi-sistem, seperti penelitian yang telah dilakukan sebelumnya oleh [3] dan [4].

\section{TINJAUAN PUSTAKA}

\section{Manajemen Inventory}

Persediaan (inventory) yaitu meliputi segala macam jenis barang jadi maupun bahan mentah yang akan digunakan untuk menunjang proses produksi serta distribusi. Bahan baku (raw material), komponen-komponen part, barang work in process dan barang finished goods 
merupakan bagian yang termasuk ke dalam persediaan, seperti halnya pada berbagai pemasok yang menjadi bagian dari proses produksi dan distribusi $[2,5]$.

Menurut [6], persediaan yang diadakan mulai dari bentuk bahan baku sampai dengan finished goods (barang jadi) yang sangat berguna untuk

1. menghilangkan risiko delay akibat barang yang dipesan datang terlambat;

2. menghilangkan risiko apabila barang tidak dalam kondisi baik saat datang;

3. melakukan penimbunan agar mudah untuk mendapatkan barang tersebut saat tidak ada di pasaran;

4. menjaga kelancaran dan stabilitas alur produksi barang;

5. mencapai penggunaan optimal dari mesin produksi;

6. menaikkan tingkat pelayanan pada pelanggan agar dapat memenuhi keinginan dan memberikan jaminan ketersediaan barang; dan

7. menjadikan jumlah yang diproduksi tidak bergantung dengan jumlah yang dijual.

\section{Pengendalian Persediaan}

Sistem pengendalian persediaan memiliki dua jenis yang berbeda, yaitu:

1. Fixed Order Quantity System atau System Continuous

Tujuan persediaan dengan metode ini adalah untuk menentukan jumlah pesanan yang paling optimal dengan biaya yang minimal dan titik pemesanan kembali (reorder point). Prinsip pengendalian persediaan sistem $\mathrm{Q}$ adalah pemesanan dilakukan pada saat mencapai batas titik pemesanan (reorder point). Jumlah masing-masing unit produk yang dipesan sudah tetap. Namun, pemesanannya dapat berbeda waktunya (kapan reorder point dapat tercapai). Jumlah persediaan yang menjadi kebutuhan selama waktu ancang-ancang dengan memperhitungkan kebutuhan yang berfluktuasi selama waktu ancang-ancang tersebut. Persediaan untuk meredam fluktuasi ini dinamakan persediaan pengaman [7]. Dapat dikatakan, safety stock dalam sistem ini diperlukan untuk mengatasi adanya fluktuasi demand selama lead time. Safety stock untuk demand probabilistik dengan stock-out case lost sales dimana demand yang tidak dapat dipenuhi akan dianggap hilang.

\section{Fixed Order Interval atau Fixed Time Periodic System}

Untuk metode ini, jumlah tiap unit yang dipesan berbeda-beda tergantung permintaan setiap unit produk. Persediaan pengaman dalam sistem ini tidak hanya dibutuhkan untuk meredam fluktuasi permintaan selama lead time, tetapi juga untuk seluruh konsumsi persediaan, sehingga dalam sistem ini menggunakan persediaan pengaman yang besar. Sistem ini biasa digunakan untuk menutup fluktuasi demand untuk stock-out case lost sales. Penggunaan metode interval pemesanan tetap akan menghemat biaya pesan. Total biaya pesan akan lebih kecil dibanding biaya pesan unit produk secara individu. Namun, penggunaan metode ini dapat mengakibatkan biaya simpan meningkat karena pemesanan dapat dilakukan pada saat persediaan unit produk masih tersedia.

Berdasarkan bentuk atau klasifikasinya, demand dibedakan menjadi dua yaitu

1. Permintaan independen merupakan permintaan yang dipengaruhi secara langsung oleh permintaan pasar. Besarnya permintaan di luar kontrol dari proses produksi perusahaan sehingga menggunakan sistem replenishment atau penambahan secara berkala dalam proses kontrol inventory-nya dan sangat membutuhkan peramalan.

2. Permintaan dependen merupakan permintaan yang tidak dipengaruhi secara langsung oleh permintaan pasar namun dipengaruhi oleh kebutuhan dari item lain yang diproduksi. Besarnya dipengaruhi oleh proses produksi sehingga peramalan produksi tidak menjadi prioritas dalam keputusan pengendalian persediaan melainkan menggunakan material requirement planning dalam proses kontrol inventori-nya.

MPS merupakan rencana induk perusahaan yang terperinci mengenai kebutuhan perusahaan dalam memproduksi masing-masing produk akhir dalam suatu periode. Pembuatan MPS dilakukan berdasarkan jumlah produk jadi yang harus diproduksi tiap periodenya agar mencapai kapasitas maksimum. MPS juga menunjukkan jumlah sisa persediaan di setiap akhir periodenya. Tiap satu 
periode, biasanya mingguan, data akan diperbarui (update) dan memiliki data untuk beberapa bulan ke depan [8]. Data MPS dapat diubah secara periodik untuk mencerminkan pesanan baru atau peramalan baru dengan berjalannya waktu.

\section{Metode Analisis ABC Persediaan}

Analisis $\mathrm{ABC}$ adalah metode dalam manajemen persediaan (inventory management) untuk mengendalikan sejumlah kecil barang, tetapi mempunyai nilai investasi yang tinggi. Menurut [9], klasifikasi $\mathrm{ABC}$ merupakan klasifikasi dari suatu kelompok material dalam susunan menurun berdasarkan biaya penggunaan material itu per periode waktu yaitu harga per unit material dikalikan volume penggunaan dari material itu selama periode tertentu, periode waktu yang umum digunakan dalam analisis $\mathrm{ABC}$ adalah satu tahun. Analisis $\mathrm{ABC}$ dapat juga diterapkan menggunakan kriteria lain, bukan hanya berdasarkan kriteria biaya, tetapi tergantung pada faktorfaktor yang menentukan kepentingan suatu material.

Analisis ABC didasarkan pada sebuah konsep yang dikenal dengan nama Hukum Pareto (Ley de Pareto). Hukum Pareto menyatakan bahwa sebuah grup selalu memiliki persentase terkecil (20\%) yang bernilai atau memiliki dampak terbesar (80\%). Pada tahun 1940-an, Ford Dickie dari General Electric mengembangkan konsep Pareto ini untuk menciptakan konsep ABC dalam klasikasi barang persediaan.

Berdasarkan hukum Pareto, analisis $\mathrm{ABC}$ dapat menggolongkan barang berdasarkan peringkat nilai dari nilai tertinggi hingga terendah, dan kemudian dibagi menjadi kelas-kelas besar terprioritas; biasanya kelas dinamai A, B, C, dan seterusnya secara berurutan dari peringkat nilai tertinggi hingga terendah. Oleh karena itu, analisis ini dinamakan analisis ABC. Umumnya, kelas A memiliki jumlah jenis barang yang sedikit, namun memiliki nilai yang sangat tinggi. Tiga kelas, yaitu A, B, dan C, dengan besaran masing-masing kelas ditentukan sebagai berikut [10].

Kelas A : Merupakan barang-barang dalam jumlah unit berkisar 15-20\% dari total seluruh barang, tetapi merepresentasikan $75-80 \%$ dari total nilai uang.

Kelas B : Merupakan barang-barang dalam jumlah unit berkisar 20-25\% dari total seluruh barang, tetapi merepresentasikan $10-15 \%$ dari total nilai uang.

Kelas C : Merupakan barang-barang dalam jumlah unit berkisar 60-65\% dari total seluruh barang, tetapi merepresentasikan 5-10\% dari total nilai uang.

\section{Metode Analisis $5 \mathrm{~W}+1 \mathrm{H}$}

Metode $5 \mathrm{~W}+1 \mathrm{H}$ merupakan salah satu analisis pemecah masalah yang baik dan melibatkan pemikiran investigasi. Pertanyaan yang ditemukan oleh Rudyard Kipling ini berupa enam pertanyaan yang juga disebut sebagai analisis $(5 \mathrm{~W}+1 \mathrm{H})$, terdiri atas beberapa pertanyaan sebagai berikut.

1. What (apa) - faktor apa yang diperbaiki?

2. Why (mengapa) - penyebab dari perbaikan yang akan dilakukan?

3. Where (di mana) - tempat melakukan peluang perbaikan?

4. When (kapan) - batas waktu pelaksanaan peluang perbaikan?

5. Who (siapa) - yang melakukan peluang perbaikan?

6. How (bagaimana) - bagaimana melakukan peluang perbaikan?

Pada tahap ini, pokok permasalah diidentifikasi dari mulai faktor yang menyebabkan permasalahan tersebut muncul hingga cara yang relevan untuk melakukan perbaikan tersebut.

\section{Safety Stock}

Safety stock atau persediaan pengaman sering disebut juga sebagai buffer stock, merupakan persediaan minimum atau persediaan yang dicadangankan yang harus tersedia di perusahaan dan hanya dapat digunakan dalam keadaan yang bersifat urgent atau darurat. Dengan adanya safety stock maka perusahaan dapat meminimumkan risiko yang dapat ditimbulkan karena adanya 
ketidakpastian kedatangan bahan baku yang dapat menyebabkan bahan baku stockout atau shortage.

Stockout atau persediaan habis disebabkan beberapa faktor yaitu: (1) demand yang fluktuatif, (2) forecast yang tidak akurat, serta (3) lead time yang bervariasi.

Perusahaan industri manufaktur harus memiliki jumlah bahan baku yang selalu tersedia dalam inventory perusahaan untuk menjamin kontinuitas atau kelangsungan proses produksi perusahaan/usahanya. Safety stock dapat ditentukan dengan menggunakan perhitungan sebagai berikut.

$$
\text { safety stock }=\text { safety factor } \times \text { standar deviasi }
$$

Namun, perhitungan safety stock tidak bersifat baku. Artinya, meski memiliki rumus perhitungan dalam menentukan angaka safety stock, setiap perusahaan memiliki kebijakan yang berbeda dalam menetapkan safety stock, salah satunya berdasarkan estimasi jumlah stock level atau safety stock ditetapkan 2 hari stock atau 20\% dari total stock. Sehingga jumlah safety stock dapat dilakukan pembaruan sesuai dengan kebutuhan perusahaan.

\section{METODE}

Metodologi yang digunakan dalam penelitian ini dapat digambarkan dalam bagan alir Gambar 1.

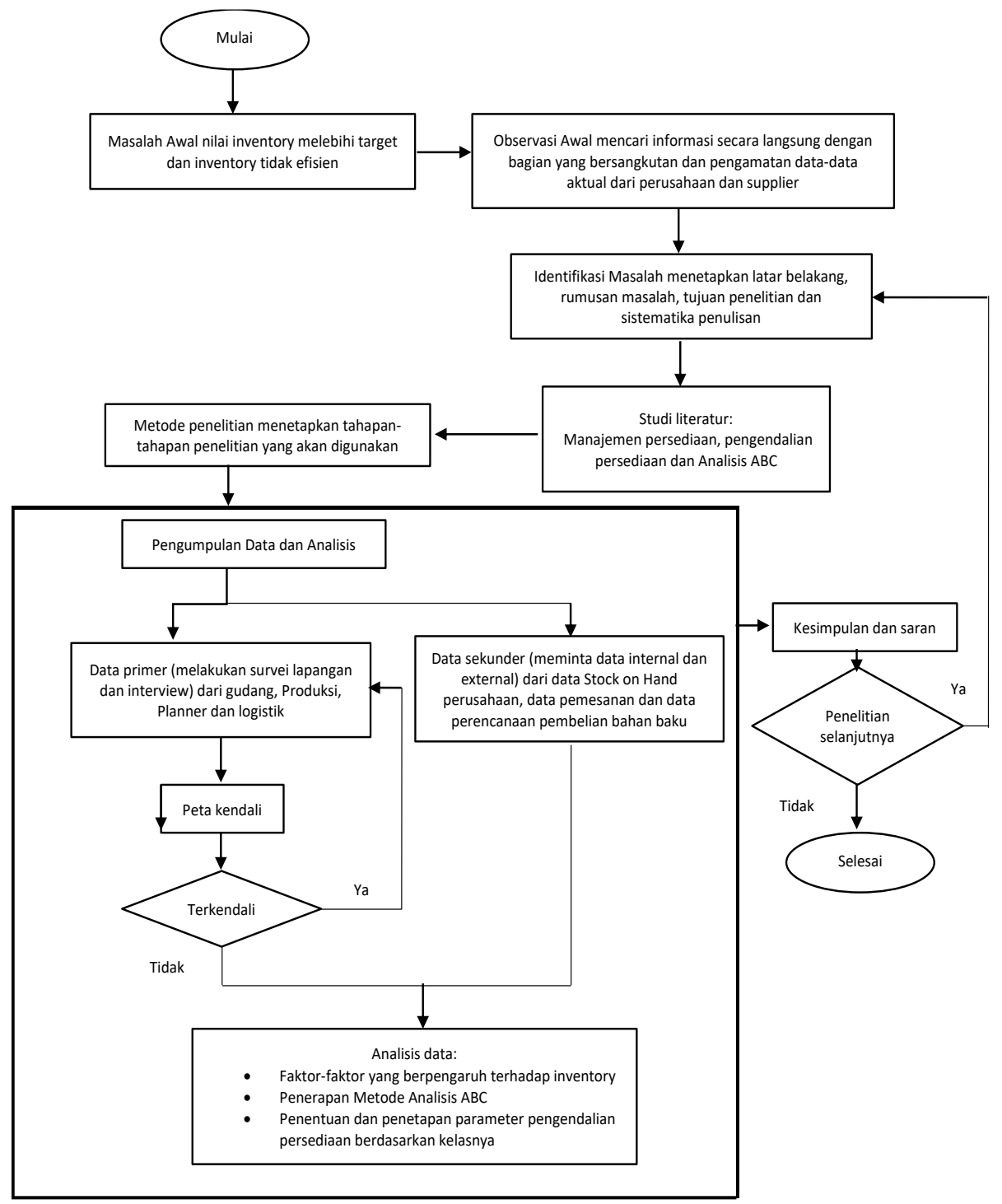

Gambar 1 Kerangka penelitian 


\section{HASIL DAN PEMBAHASAN}

Nilai inventory perusahaan saat dilakukan penelitian lebih besar dari target maksimum perusahaan. Di setiap bulannya selalu dalam kondisi over value, namun jika diuraikan berdasarkan figure atau berdasarkan jenisnya dapat dilihat pada Gambar 2.
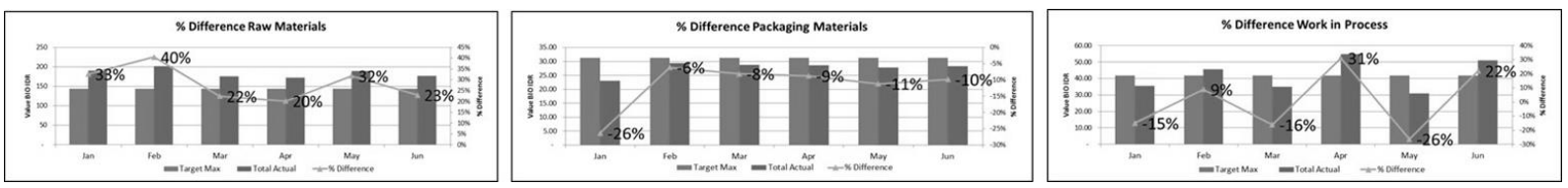

Gambar 2 Persentase perbedaan nilai total persediaan terhadap target max perusahaan

Dari Gambar 2 diketahui bahwa:

1. Value Total Actual $>20 \%-40 \%$ dari Target Maximum $\rightarrow$ Not GOOD condition

2. Value Total Actual $<6 \%-26 \%$ dari Target Maximum $\rightarrow$ GOOD condition

3. Fast Moving $\rightarrow$ tidak berpengaruh terhadap nilain inventory perusahaan

Jenis bahan baku yang digunakan di pabrik foods (data jumlah dan value pada bulan Juni) diperlihatkan dalam Tabel 1 .

Tabel 1 Jenis bahan baku pada stock on hand

\begin{tabular}{llrr}
\hline Jenis Bahan Baku & UoM & Quantity & Value (IDR) \\
\hline Beverage & KG & 818.032 & 32.230 .884 .257 \\
Spread and Savoury Lokal & KG & 907.942 & 19.104 .521 .701 \\
Spread and Savoury Impor & KG & 241.932 & 5.841 .987 .807 \\
Spread and Savoury Commodity & KG & 9.895 .840 & 118.946 .742 .142 \\
\hline Total Raw Materials & KG & 11.863 .745 & 176.124 .135 .907 \\
\hline
\end{tabular}

Dari Tabel 1 diketahui bahwa:

1. Bahan baku beverage $\rightarrow$ perbedaan tempat produksi, gudang, dan sifat bahan baku yang khusus

2. Spread and savoury commodity $\rightarrow$ manajeman dilakukan oleh Unilever Global sehingga bahan baku ini bersifat uncontrollable

Maka untuk kedua jenis bahan baku ini tidak dilakukan penelitian lebih lanjut.

Jenis bahan baku yang dapat dilakukan perbaikan adalah bahan baku Spread and Savoury yang dibedakan berdasarkan asal pemasok yaitu lokal dan impor, untuk skala prioritas dari kedua jenis bahan baku ini berdasarkan bobotnya ditunjukkan dalam Tabel 2.

Tabel 2 Perbandingan bahan baku lokal dan bahan baku impor

\begin{tabular}{llrrrrr}
\hline Jenis & UoM & Quantity & Value IDR & Item & Bobot Qty & Bobot value \\
\hline Lokal & KG & 907.942 & 19.104 .521 .701 & 134 & 6.776 & 142.571 .057 \\
Impor & KG & 241.932 & 5.841 .987 .807 & 26 & 9.305 & 224.691 .839 \\
\hline Total & KG & 1.149 .874 & 24.946 .509 .508 & 160 & 16.081 & 367.262 .896 \\
\hline
\end{tabular}

Dari Tabel 2 diketahui bahwa:

1. Spread and Savoury Lokal $\rightarrow$ Bobot Rendah

2. Spread and Savoury Impor $\rightarrow$ Bobot Tinggi

Dari perbandingan bobotnya maka penelitian fokus pada bahan baku impor.

Berdasarkan konsep hukum Pareto, metode analisis ABC pada persediaan menggolongkan atau mengklasifikasikan bahan baku berdasarkan persentase kebutuhan dan nilai dari bahan baku tersebut. Penelitian ini fokus terhadap permasalahan pada bahan baku impor yang kurang efisien. Berikut 8 tahapan analisis ABC persediaan.

1. Menentukan bahan baku impor yang digunakan dan akan dianalisis.

2. Menentukan harga per unit bahan baku impor.

3. Mengalikan harga per unit dengan stock yang ada di perusahaan. 
4. Menyusun bahan baku menurut besarnya total nilai uang, dengan urutan pertama adalah bahan baku dengan value paling besar.

5. Menghitung persentase value barang dari banyaknya tipe barang dan total nilai uang.

6. Menghitung persentase kumulatif nilai uang dari banyaknya nilai barang.

7. Membentuk kelas-kelas berdasarkan persentase jumlah barang dengan persentase nilai uang.

8. Menggambarkan kurva analisis $\mathrm{ABC}$ (dengan bagan Pareto) atau menunjukkan tingkat kepentingan masalah.

Tabel 3 memperlihatkan hasil analisis ABC persediaan bahan baku impor.

Selanjutnya kurva berdasarkan persentase dan kelas berdasarkan analisis ABC dapat dilihat pada Gambar 3.

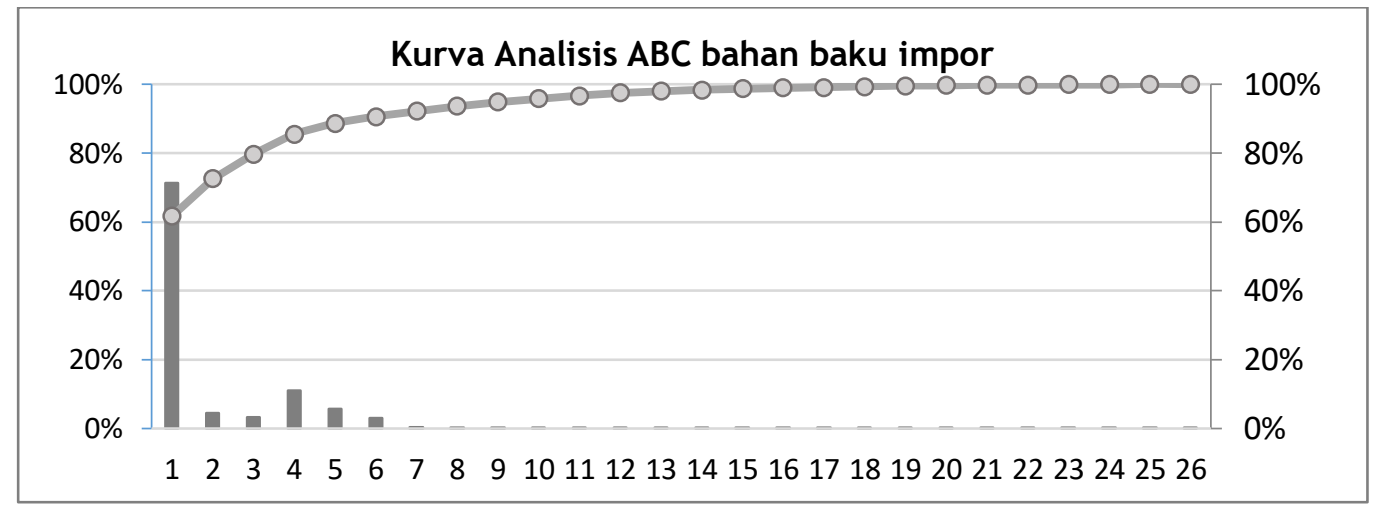

Gambar 3 Kurva analisis ABC bahan baku impor

Gambar 3 merupakan grafik Pareto yang menunjukkan kurva analisis $\mathrm{ABC}$ bahan baku impor. Dengan kurva ini maka penentuan kelas $\mathrm{ABC}$ pada bahan baku impor sudah sangat jelas terlihat. Pengelompokan kelas bahan baku impor setelah dilakukan analisis ABC, pengelompokan atau kelas bahan baku impor akan digunakan untuk menetapkan perlakuan atau kontrol terhadap bahan baku impor [9]. Pengelompokan kelas berdasarkan analisis ABC digunakan untuk menetapkan:

a. frekuensi perhitungan inventory (cycle count) untuk bahan baku impor kelas A harus ditinjau lebih ketat dalam akurasi catatan inventory dibandingkan dengan material kelas $\mathrm{B}$ dan $\mathrm{C}$;

b. skala prioritas bahan baku impor kelas A dan B memberikan petunjuk dengan tepat dalam meningkatkan program efisiensi atau penurunan biaya inventory yang perlu difokuskan pada bahan baku impor yang tergabung dalam kelas A dan B;

c. prioritas dalam aktivitas pembelian bahan baku impor difokuskan terhadap bahan baku yang bernilai tinggi dan konsumsi penggunaan dalam jumlah tinggi, hal ini tepat dilakukan pada bahan baku kelas A;

d. sistem penjadwalan dan pengendalian bahan baku impor dengan klasifikasi $\mathrm{ABC}$ membantu mengidentifikasi metode pengendalian yang digunakan. Bahan baku kelas A dan B harus dilakukan pengendalian dengan metode yang lebih baik dibandingkan dengan kelas $\mathrm{C}$; dan

e. proses pengendalian persediaan dan penjadwalan pasokan bahan baku impor untuk kelas A harus ditinjau ulang dalam pembuatan keputusan, waktu pembelian, waktu kedatangan, jumlah stock pengamanan dan untuk kelas B akan lebih baik jika perlakuan yang sama pada kelas A diterapkan di kelas B dan C.

Setelah dilakukan analisis $\mathrm{ABC}$ pada bahan baku impor dan kelas $\mathrm{ABC}$ sudah diketahui maka untuk efisiensi pada pengendalian persediaan dan penjadwalan pasokan bahan baku impor akan diterapkan metode brainstorming. Metode ini digunakan setelah proses observasi yang dilakukan sebelum dan sesudah penelitian analisis ABC pada bahan baku impor. Metode brainstorming yang dimaksud adalah melakukan tracking bahan baku impor dengan perhitungan frozen horizon.

Departemen terkait pada penelitian ini adalah departemen supply chain procurement, material progressor, warehouse, dan logistic. Untuk melakukan perhitungan frozen horizon maka 
diperlukan data dari logistic dan departemen lain yang akan digunakan dalam menyelesaikan perhitungan frozen horizon.

Tabel 3 Analisis ABC persediaan bahan baku impor

\begin{tabular}{|c|c|c|c|c|c|c|c|c|}
\hline No. Material Description & UoM & Quantity & Price & $\begin{array}{r}\text { Value } \\
\text { (Bio IDR) }\end{array}$ & $\%$ Quantity & $\%$ Value & $\begin{array}{r}\% \text { Cummu- } \\
\text { lative }\end{array}$ & $\%$ Class \\
\hline 1 Canola Oil & KG & 4.151 .580 & 15.174 & 63,00 & 71,22 & 61,65 & 61,65 & \\
\hline 2 Onion Pwd & KG & 267.243 & 41.778 & 11,16 & 4,58 & 10,93 & 72,57 & $80 \%$ \\
\hline 3 Garlic Powder & KG & 194.438 & 37.722 & 7,33 & 3,34 & 7,18 & 79,75 & \\
\hline 4 Cornflour & KG & 635.002 & 9.267 & 5,88 & 10,89 & 5,76 & 85,51 & \\
\hline 5 Maltodextrine & KG & 329.391 & 9.865 & 3,25 & 5,65 & 3,18 & 88,69 & \\
\hline 6 Cornstarch & KG & 173.574 & 11.573 & 2,01 & 2,98 & 1,97 & 90,66 & \\
\hline 7 GISTEX XII & KG & 17.433 & 90.878 & 1,58 & 0,30 & 1,55 & 92,21 & $\begin{aligned} 16 \% \\
\mathrm{P}\end{aligned}$ \\
\hline 8 Sunflower Oil & KG & 3.957 & 355.193 & 1,41 & 0,07 & 1,38 & 93,58 & D \\
\hline 9 Vitamin E & KG & 2.581 & 483.560 & 1,25 & 0,04 & 1,22 & 94,80 & \\
\hline 10 Chili Extrak Powder & KG & 4.659 & 227.233 & 1,06 & 0,08 & 1,04 & 95,84 & \\
\hline 11 Sweet Corn Powder & KG & 8.494 & 104.000 & 0,88 & 0,15 & 0,86 & 96,70 & \\
\hline 12 Ginger Powder & KG & 7.251 & 105.758 & 0,77 & 0,12 & 0,75 & 97,45 & \\
\hline 13 Oleoresin Paprika & KG & 2.099 & 265.000 & 0,56 & 0,04 & 0,54 & 98,00 & \\
\hline 14 Corn Kernel & KG & 2.425 & 161.706 & 0,39 & 0,04 & 0,38 & 98,38 & \\
\hline 15 Celery Seed Powder & KG & 7.281 & 40.223 & 0,29 & 0,12 & 0,29 & 98,67 & \\
\hline 16 HPP CM & KG & 3.790 & 72.112 & 0,27 & 0,07 & 0,27 & 98,94 & \\
\hline 17 SHALLOT PWD & KG & 882 & 230.737 & 0,20 & 0.02 & 0,20 & 99,14 & \\
\hline 18 PAPRIKA PWD & KG & 1.171 & 172.922 & 0,20 & 0,02 & 0,20 & 99,33 & $4 \%$ \\
\hline 19 Tomato Pasta & KG & 12.851 & 14.538 & 0,19 & 0,22 & 0,18 & 99,52 & $\mathrm{C}$ \\
\hline 20 Ginger Oil & KG & 178 & 772.070 & 0,14 & 0,00 & 0,13 & 99,65 & \\
\hline 21 Paprika Aquaresin & KG & 156 & 719.103 & 0,11 & 0,00 & 0,11 & 99,76 & \\
\hline 22 GARLIC Oil & KG & 1.216 & 84.528 & 0,10 & 0,02 & 0,10 & 99,86 & \\
\hline 23 SOY SAUCE & KG & 262 & 307.163 & 0,08 & 0,00 & 0,08 & 99,94 & \\
\hline 24 Carrot Granukes & KG & 777 & 34.936 & 0,03 & 0,01 & 0,03 & 99,97 & \\
\hline 25 Parsley Flakes & KG & 289 & 65.588 & 0,02 & 0,00 & 0,02 & 99,98 & \\
\hline 26 Thyme-Ground & KG & 77 & 205.990 & 0,02 & 0,00 & 0,02 & 100,00 & \\
\hline Total & & 5.829 .058 & & 102,19 & & 100 & & \\
\hline
\end{tabular}

Dari data logistik dapat diketahui setiap tahap poses pengiriman dari supplier. Dari data ini dapat dilakukan tracking secara lengkap dari setiap bahan baku impor berdasarkan nomor purchase order dari setiap bahan baku impor. Setelah dilakukan tracking bahan baku impor, dapat disimpulkan bahwa setiap bahan baku impor memiliki beberapa tahapan proses pengiriman yakni mulai dikirim dari negara asal supplier sampai tiba di perusahaan. Tahapan impor bahan baku yang harus dilewati ada 4 tahapan sebagiamana diperlihatkan dalam Gambar 4, yaitu:

1. On Vessel: Waktu yang dibutuhkan dalam proses pengiriman barang hingga sampai di port (pelabuhan) negara asal.

2. Intransit Time (IT): Waktu yang dibutuhkan dalam proses pengiriman barang dari pelabuhan negara asal sampai tiba di pelabuhan Indonesia.

3. Clearance Time: Waktu yang dibutuhkan dalam proses perizinan barang masuk ke Indonesia (bea cukai/BC).

4. Quality Checking (QC): Waktu yang dibutuhkan dalam proses pengecekan kualitas bahan baku

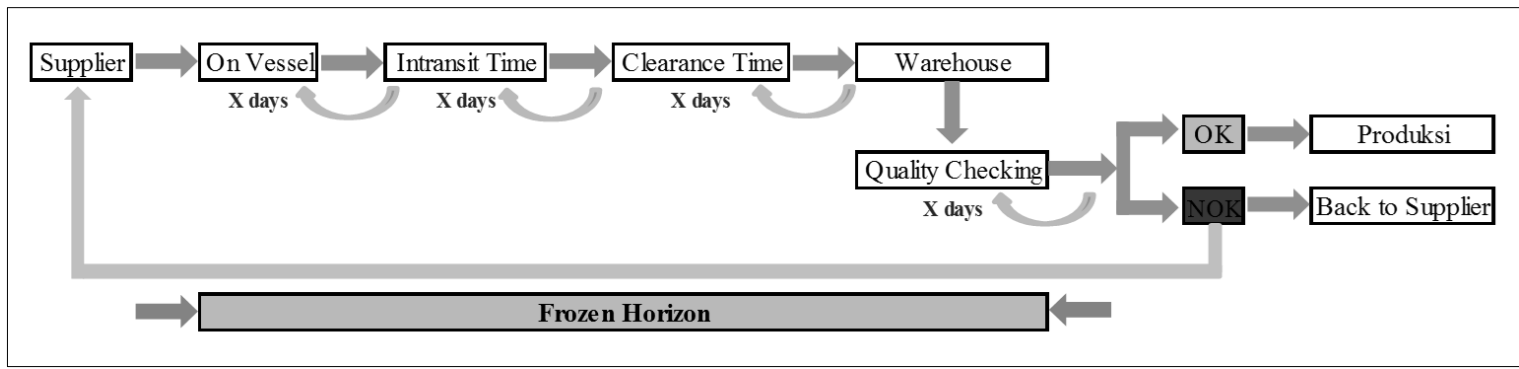

Gambar 4 Skema perhitungan frozen horizon 
Dengan data tracking yang telah diketahui maka dapat dihitung kebutuhan waktu dari setiap tahapan pengiriman bahan baku impor. Setelah diketahui waktu keseluruhan maka jumlah waktu tersebut dapat digunakan sebagai data khusus untuk pengendalian persediaan dan pengaturan penjadwalan bahan baku impor. Hasilnya ditunjukkan pada Tabel 4.

Tabel 4 Data frozen horizon bahan baku impor

\begin{tabular}{|c|c|c|c|c|c|c|c|c|c|}
\hline \multirow[t]{2}{*}{ No Material Description } & \multirow[t]{2}{*}{ Supplier } & \multirow{2}{*}{$\begin{array}{l}\text { Original } \\
\text { Country }\end{array}$} & \multicolumn{6}{|c|}{ In Days } & \multirow{2}{*}{ Class } \\
\hline & & & Vessel & IT & $\mathrm{BC}$ & QC & $\mathrm{FH}$ & LT & \\
\hline 1 Canola Oil & WG & Australia & 6 & 20 & 7 & 2 & 35 & 75 & \multirow{3}{*}{ A } \\
\hline 2 Onion Pwd & $\mathrm{BCF}$ & China & 11 & 12 & 7 & 7 & 37 & 90 & \\
\hline 3 Garlic Powder & SDEF & China & 12 & 12 & 5 & 7 & 36 & 80 & \\
\hline 4 Cornflour & JCBM & China & 10 & 14 & 5 & 7 & 36 & 90 & \multirow{7}{*}{ B } \\
\hline 5 Maltodextrine & QLS & China & 10 & 14 & 5 & 7 & 36 & 91 & \\
\hline 6 Cornstarch & PESB & Malaysia & 3 & 4 & 5 & 7 & 19 & 75 & \\
\hline 7 GISTEX XII & $\mathrm{BCF}$ & China & 10 & 31 & 7 & 2 & 50 & 90 & \\
\hline 8 Sunflower Oil & BSEA & Singapore & 14 & 35 & 7 & 2 & 58 & 90 & \\
\hline 9 Vitamin E & ZM & China & 5 & 20 & 4 & 7 & 36 & 91 & \\
\hline 10 Chili Extrak Powder & $\mathrm{PF}$ & Thailand & 6 & 6 & 7 & 7 & 26 & 90 & \\
\hline 11 Sweet Corn Powder & CFL & New Zealand & 6 & 30 & 7 & 7 & 50 & 91 & \multirow{16}{*}{$\mathrm{C}$} \\
\hline 12 Ginger Powder & NPV & Vietnam & 6 & 7 & 4 & 7 & 24 & 90 & \\
\hline 13 Oleoresin Paprika & SI & India & 5 & 14 & 6 & 2 & 27 & 91 & \\
\hline 14 Corn Kernel & SF & India & 12 & 12 & 7 & 7 & 38 & 91 & \\
\hline 15 Celery Seed Powder & SSMP & India & 10 & 18 & 7 & 7 & 42 & 90 & \\
\hline 16 HPP CM & UAPL & China & 7 & 31 & 7 & 2 & 47 & 91 & \\
\hline 17 SHALLOT PWD & $\mathrm{PF}$ & Thailand & 6 & 6 & 7 & 7 & 26 & 56 & \\
\hline 18 PAPRIKA PWD & QR & Thailand & 7 & 6 & 4 & 7 & 24 & 91 & \\
\hline 19 Tomato Pasta & UAPL & China & 6 & 11 & 16 & 7 & 40 & 91 & \\
\hline 20 Ginger Oil & SI & India & 5 & 14 & 6 & 7 & 32 & 90 & \\
\hline 21 Paprika Aquaresin & KI & USA & 10 & 6 & 4 & 7 & 27 & 91 & \\
\hline 22 GARLIC Oil & $\mathrm{BF}$ & Thailand & 7 & 6 & 4 & 7 & 24 & 91 & \\
\hline 23 SOY SAUCE & DFS & Netherlands & 11 & 12 & 7 & 7 & 37 & 75 & \\
\hline 24 Carrot Granukes & RSG & Germany & 6 & 3 & 13 & 7 & 29 & 90 & \\
\hline 25 Parsley Flakes & KMG & Germany & 3 & 5 & 6 & 7 & 21 & 90 & \\
\hline 26 Thyme-Ground & KMG & Germany & 3 & 5 & 6 & 7 & 21 & 90 & \\
\hline 27 Onion powder & $\mathrm{BCF}$ & China & 11 & 12 & 7 & 7 & 37 & 90 & \multirow{5}{*}{$\begin{array}{l}\text { Pembaruan } \\
\text { bahan baku }\end{array}$} \\
\hline 28 Gistex & DFS & Netherlands & 10 & 31 & 7 & 2 & 50 & 75 & \\
\hline 29 Oil Garlic & $\mathrm{BF}$ & Thailand & 7 & 6 & 4 & 7 & 24 & 91 & \\
\hline 30 Paprika Powder & QR & Thailand & 7 & 6 & 4 & 7 & 24 & 91 & \\
\hline 31 Sweet corn pdw & CFL & New Zealand & 6 & 30 & 7 & 7 & 50 & 91 & \\
\hline
\end{tabular}

Data pemesanan bahan baku yang telah dibuat sebelumnya, yaitu sebanyak 57 PO, dilakukan perhitungan untuk penjadwalan pasokannya berdasarkan waktu frozen horizon pada setiap nomor PO dengan mengikuti langkah-langkah perhitungan yang telah dijelaskan. Diketahui action atau tindakan yang harus dilakukan:

1. No reschedule: merupakan PO dengan remaining time atau waktu yang tersisa kurang dari waktu frozen horizon sehingga tidak bisa dilakukan penjadwalan ulang (tetap mengikuti jadwal awal), diketahui $32 \mathrm{PO}$ no reschedule atau sebanyak $56 \%$.

2. Need to postpone: merupakan PO yang bisa di-reschedule mundur lebih lama dari jadwal awal, $10 \mathrm{PO}$ atau sebanyak $18 \% \mathrm{PO}$ yang bisa di postpone.

3. Need to expedite: merupakan PO yang bisa di-reschedule maju atau lebih cepat dari jadwal awal, diketahui $3 \mathrm{PO}$ atau sebanyak 5\% yang bisa di-postpone.

4. OK: merupakan PO yang tidak perlu diubah jadwalnya, karena jadwal awal PO sesuai dengan kebutuhan bahan baku, diketahui 12 PO atau sebanyak 57\% dengan jadwal yang sesuai.

Tindakan perbaikan yang harus dilakukan, dengan perhitungan waktu frozen horizon yang bisa reschedule hanya yang memiliki remaining time lebih besar atau sama dengan waktu frozen horizon, sehingga action yang dilakukan lebih tepat dan efisien. Perbandingan penentuan tindakan reschedule $\mathrm{PO}$ dengan dan tanpa perhitungan waktu frozen horizon adalah: 
1. Need to postpone: tanpa perhitungan waktu frozen horizon sebanyak 56\% PO harus postpone pengirimannya sedangkan dengan frozen horizon yang bisa di-postpone hanya $18 \%$ karena remaining time $\mathrm{PO}$ dengan waktu lebih besar dari frozen horizon dan dapat di-reschedule postpone hanya $18 \%$.

2. Need to expedite: tanpa perhitungan waktu frozen horizon sebanyak $23 \%$ PO harus percepat atau expedite pengirimannya sedangkan dengan frozen horizon yang bisa di-expedite hanya 5\% karena remaining time PO dengan waktu lebih besar dari frozen horizon dan dapat direschedule postpone hanya $5 \%$.

3. OK: dengan atau tanpa perhitungan waktu frozen horizon sebanyak $21 \%$ PO tidak memerlukan reschedule.

4. No Reschedule: tanpa perhitungan waktu frozen horizon semua PO bisa di-reschedule sedangkan dengan perhitungan waktu frozen horizon yang bisa reschedule hanya yang memiliki remaining time lebih besar atau sama dengan waktu frozen horizon.

Dengan data frozen horizon, kemudian diaplikasikan dengan data pemesanan bahan baku impor pada data MRP sehingga akan diketahui bahan baku impor yang mana saja yang masih bisa dilakukan reschedule atau pengaturan ulang jadwal kedatangan.

1. Langkah pertama: Untuk mengetahui PO dapat di-reschedule atau tidak tentukan terlebih dahulu nilai yang lebih kecil antara current delivery plan atau revision delivery date. Yang digunakan untuk perhitungan selanjutnya adalah nilai yang lebih kecil, nilai yang lebih kecil jika tanggal current delivery plan sama dengan revision delivery date maka delivery date sudah sesuai atau no reschedule (tidak dilakukan penjadwalan ulang).

2. Langkah kedua: Tentukan waktu yang tersisa sebelum bahan baku dibutuhkan, dimisalkan sebagai nilai X (remaining time), didapatkan dari:

$$
\begin{aligned}
& \text { (Current delivery plan) Today } \\
& \mathrm{X}=\underset{\text { (Revision delivery date) }}{\text { or }} \quad-\text { (tanggal ketika update) }
\end{aligned}
$$

Kesimpulan nilai $\mathrm{X}$ :

a. Jika nilai $\mathrm{X}$ lebih besar dari frozen horizon maka: PO bisa dilakukan penjadwalan ulang atau reschedule (ikuti langkah ketiga).

b. Jika nilai X lebih kecil dari frozen horizon maka: PO tidak bisa dilakukan penjadwalan ulang atau no reschedule.

3. Langkah ketiga: Membuat kesimpulan kedua untuk bahan baku yang bisa di-reschedule:

a. Jika tanggal revision delivery date lebih cepat daripada current delivery plan maka bahan baku tersebut need to expedite artinya bahan baku tersebut dapat di datangkan lebih cepat dari rencana kedatangan awal.

b. Jika tanggal revision delivery date lebih lama daripada current delivery plan maka bahan baku tersebut need to postpone artinya bahan baku tersebut dapat didatangkan mundur atau kedatangannya ditunda dari rencana kedatangan awal.

Metoda analisis $\mathrm{ABC}$ persediaan digunakan untuk mengetahui skala prioritas setiap bahan baku agar perbaikan lebih tepat dilakukan sesuai kelasnya atau prioritasnya. Setelah kelas bahan baku diketahui maka langkah perbaikan selanjutnya adalah melakukan tracking dan rescheduling pasokan bahan baku impor sesuai kebutuhan perusahaan perbaikan ini dilakukan setelah observasi kepada pihak terkait dan dengan brainstorming maka pemilihan tindakan yang paling tepat untuk perbaikan dengan tracking dan rescheduling pasokan bahan baku impor sesuai dengan kelasnya yaitu:

1. Bahan baku kelas A dilakukan pengendalian persediaan dengan melakukan pengaturan penjadwalan pasokan secara parsial dengan menggunakan fixed time period system atau system periodic yang dilakukan dengan waktu perhitungan pemesanan kembali.

2. Bahan baku kelas B dengan jumlah stok lebih tinggi dari kebutuhan per bulannya seperti kelas A maka dilakukan pengaturan penjadwalan pasokan dengan fixed order quantity system atau sistem kontinu. Sistem ini dilakukan pada tiga bahan baku dengan jumlah kebutuhan paling banyak di kelas B yaitu cornflour, maltodextrine, dan cornstarch. Sedangkan bahan baku kelas 
B dengan jumlah stok lebih tinggi dari kebutuhan per bulannya dilakukan pengaturan penjadwalan pasokan dengan sistem fixed order quantity system atau sistem kontinu dengan jumlah quantity yang sama sesuai MOQ yang dipesan ketika sudah dibutuhkan pada waktu tertentu.

3. Bahan baku kelas $\mathrm{C}$ memiliki jumlah stok yang lebih besar dari jumlah kebutuhan per bulan. Untuk bahan baku kelas C diterapkan pengendalian pasokan seperti pada bahan baku kelas B dengan jumlah stok lebih tinggi dari kebutuhan per bulannya sehingga dilakukan pengaturan penjadwalan pasokan dengan sistem fixed order quantity system atau sistem kontinu.

Bahan baku impor dengan negara asal supplier yang berbeda dan memiliki beberapa tahapan proses dokumen impor menyebabkan perbedaan waktu sehingga dalam melakukan tracking dan rescheduling dibutuhkan perhitungan waktu atau estimasi waktu bahan baku dikirim dari supplier atau waktu delivery. Dalam penelitian ini, perhitungan waktu delivery dilakukan dengan menggunakan data dari departemen logistik bahan baku impor dan melakukan perhitungan estimasi waktu di setiap tahapannya yang mengacu ke data historis pengiriman bahan baku tersebut. Dalam penelitian hasil perhitungan waktu delivery yang telah dilakukan dinamakan dengan waktu frozen horizon.

Setelah semua data pembelian bahan baku impor di-tracking dan diaplikasikan ke dalam waktu frozen horizon akan diketahui nomor PO bahan baku yang masih bisa dilakukan rescheduling, sehingga di bulan berikutnya jumlah stok diharapkan sesuai dengan kebutuhan baik bahan baku tersebut dipercepat pengirimannya ataupun ditunda. Untuk menentukan hasil akhir penelitian maka data yang akan di analisis adalah data pemenuhan stok bahan baku impor terhadap kebutuhan selama tahun 2016, dimulai dari Januari-Juni, merupakan 6 bulan pertama sebelum penelitian dilakukan dan Juli-Desember, merupakan 6 bulan setelah penelitian dilakukan.

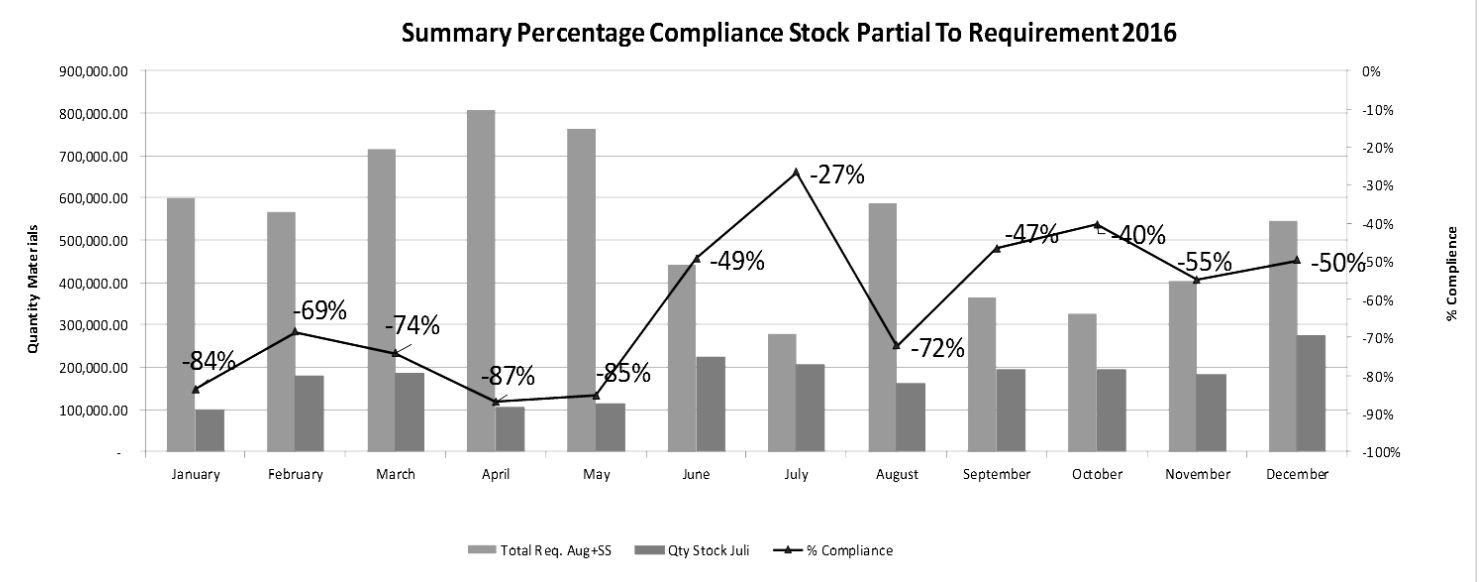

Gambar 5 Persentase pemenuhan stok parsial terhadap kebutuhan Tahun 2016

Gambar 5 menunjukkan adanya perbaikan setelah dilakukannya penelitian. Terlihat dari flow grafik line di 6 bulan pertama dengan persentase kekurangan quantity stok terhadap kebutuhan per bulannya dengan rata-rata $-75 \%$ (minus $75 \%$ ), jumlah stok terlalu sedikit dan jumlah safety stock kurang diperhitungkan dari total kebutuhan sehingga berpotensi besar mengalalami shortage atau stock-out. Berdasarkan hasil analisis ABC maka bahan baku dengan pengiriman parsial dilakukan untuk bahan baku kelas A dan kelas B dengan jumlah kebutuhan tertinggi. Sehingga, jika terjadi shortage atau stockout akan sangat merugikan karena dampak yang lebih besar bisa terjadi jika bahan baku shortage, salah satunya adalah produksi berhenti beroperasi akibat kekurangan bahan baku.

Setelah dilakukan penelitian dan perbaikan yang diterapkan selama 6 bulan, terlihat perubahan secara bertahap dengan persentase kekurangan quantity stock bahan baku dengan ratarata $-48 \%$ dari hasil 6 bulan penelitian, sehingga pemenuhan kebutuhan bahan baku yang dilakukan secara parsial sangat mungkin dilakukan. Dengan demikian, penelitian ini mengurangi risiko shortage sebanyak 26\% dan jumlah safety stock selalu dipertimbangkan. Safety stock akan membantu pemenuhan kebutuhan produksi jika terjadi keterlambatan pengiriman bahan baku 
impor dari supplier atau keterlambatan pemenuhan dokumen impor maka safety stock dapat digunakan dan produksi tetap beroperasi.

Gambar 6 menunjukkan adanya perbaikan setelah dilakukannya penelitian. Terlihat dari flow grafik line di 6 bulan pertama dengan persentase kelebihan quantity stok bahan baku dengan rata-rata 64\%, jumlah stok melebihi kebutuahan mengakibatkan penambahan cost atau biaya penyimpanan. Berdasarkan hasil analisis $\mathrm{ABC}$ maka bahan baku dengan pengiriman nonparsial termasuk bahan baku kelas $\mathrm{C}$ dan bahan baku kelas $\mathrm{B}$ dengan jumlah kebutuhan yang tidak terlalu banyak per bulannya.

Bahan baku kelas $\mathrm{C}$ memiliki jumlah MOQ atau minimum order quantity jauh lebih banyak dibandingkan kebutuhan per bulannya maka bahan baku kelas $\mathrm{C}$ dengan jumlah stok yang banyak berpotensi untuk destroyed karena masa self life bahan baku impor tidak terlalu lama sehingga berpotensi expired atau sudah melewati tanggal kadaluasa sebelum dibutuhkan untuk produksi. Tindakan destroyed merupakan suatu kerugian karena membutuhkan biaya tambahan untuk melakukan destroyed dan biaya penyimpanan selama di gudang menjadi beban cost yang harus dibayar.

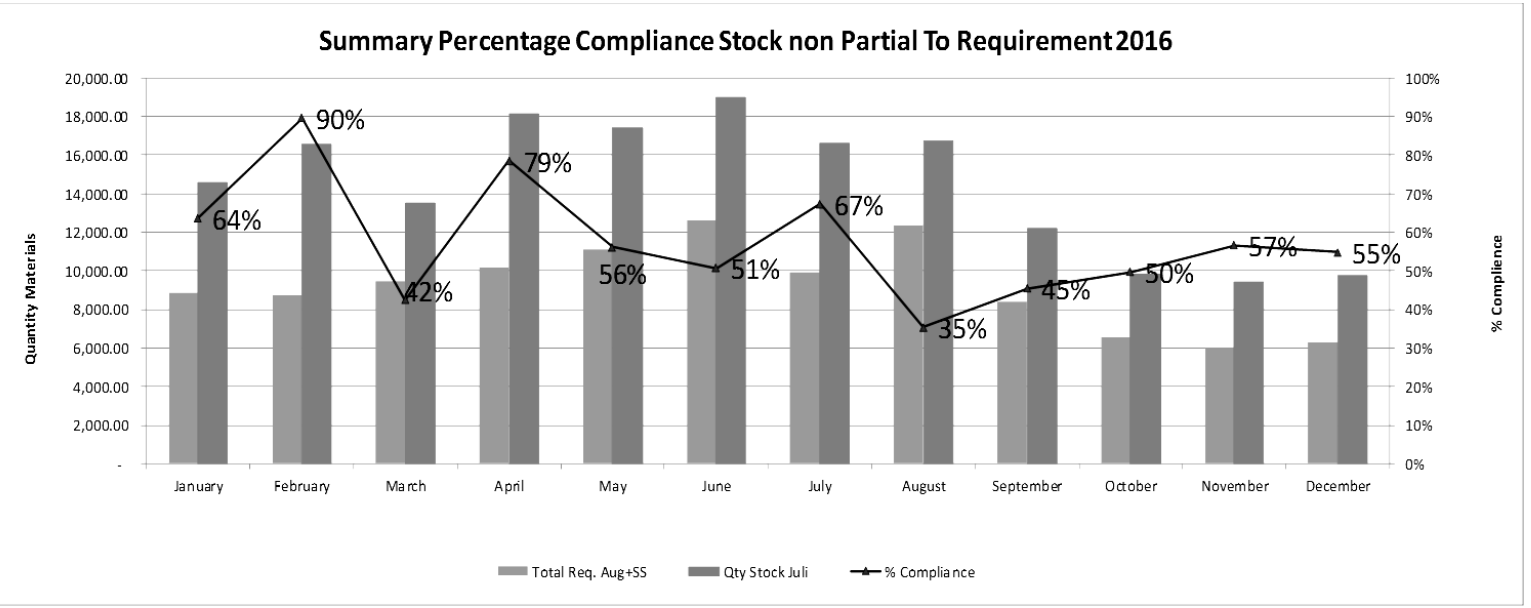

Gambar 6 Persentase pemenuhan stok nonparsial terhadap kebutuhan tahun 2016

Setelah dilakukan penelitian dan perbaikan yang diterapkan selama 6 bulan, terlihat perubahan secara bertahap dengan persentase kelebihan stock rata-rata 52\% dari hasil 6 bulan penelitian, sehingga pemenuhan kebutuhan bahan baku yang dilakukan secara nonparsial sangat mungkin dilakukan dengan dilakukannya pembaruan secara bertahap dan melakukan penjadwalan ulang kepada pemasok sesuai kebutuhan. Sehingga, penelitian ini mengurangi overstock sebanyak $12 \%$ dan jumlah safety stock selalu dipertimbangkan.

Sedangkan jumlah stock yang dikonversikan ke dalam Rupiah Indonesia berdasarkan standar harga per unit yang didapatkan dari team finance perusahaan didapatkan data dalam grafik pada Gambar 7. Gambar 7 menunjukkan perubahan value IDR stock terhadap kebutuhan per bulannya. Hal itu terlihat dari flow grafik line di 6 bulan pertama dengan persentase value melebihi kebutuhan per bulannya rata-rata 44\% lebih tinggi dari total kebutuhan atau senilai IDR 2,2 miliar. Setelah dilakukan penelitian dan perbaikan yang diterapkan selama 6 bulan, terlihat perubahan secara bertahap dengan persentase value melebihi kebutuhan per bulannya dengan rata-rata $21 \%$ lebih tinggi dari total kebutuhan atau senilai IDR 1,2 miliar dari hasil 6 bulan penelitian. Sehingga, pemenuhan kebutuhan bahan baku yang dilakukan secara parsial dan nonparsial sangat mungkin dilakukan. Dengan dilakukan pembaruan secara bertahap dan melakukan penjadwalan ulang kepada pemasok sesuai kebutuhan, penelitian ini dapat mengurangi value inventory sebanyak $23 \%$ atau senilai IDR 5,9 miliar atau sekitar IDR 1 miliar dapat diturunkan value-nya tanpa menimbulkan masalah lain dan tanpa merubah jadwal produksi sehingga performa inventory dan perusahaan tepat terjaga dengan baik. 


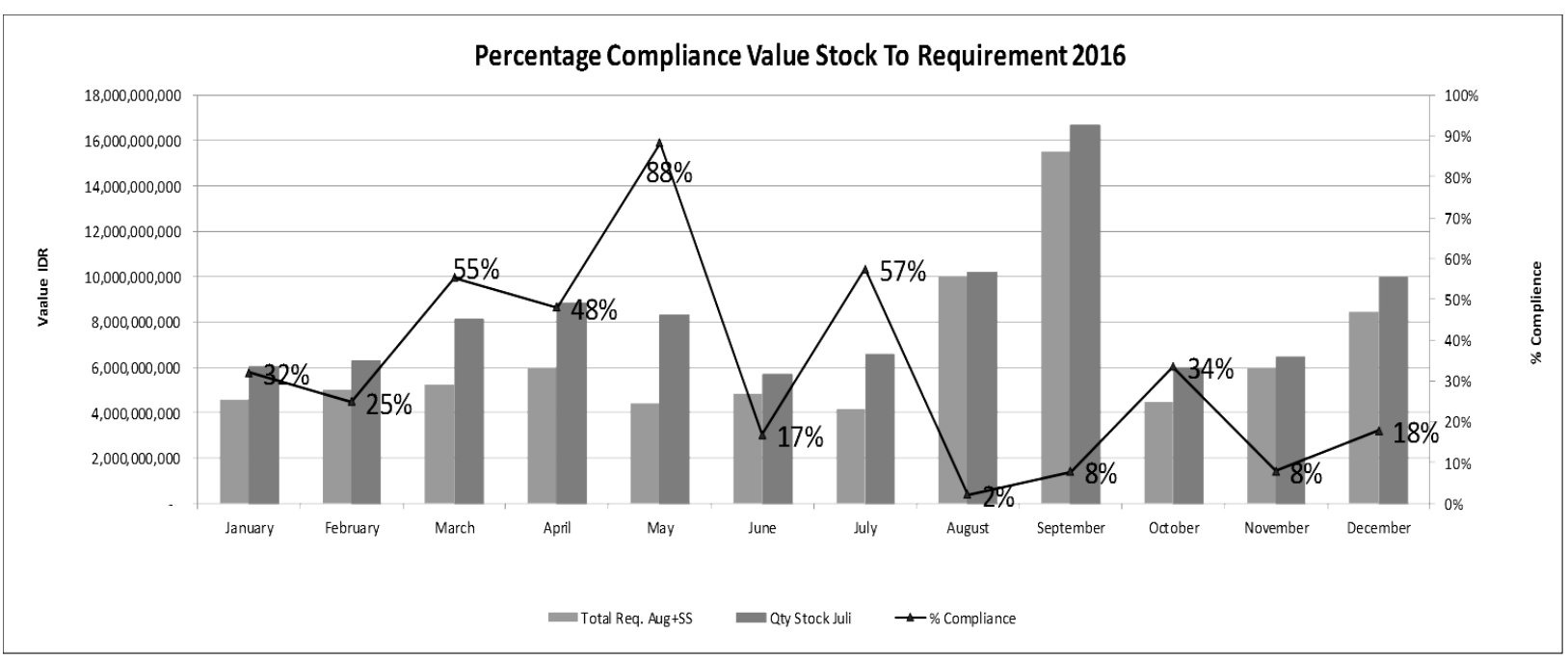

Gambar 7. Persentase value pemenuhan stock terhadap value kebutuhan

Analisis $5 \mathrm{~W}+1 \mathrm{H}$ dilakukan supaya semua peluang perbaikan dari beberapa faktor dapat terlihat dengan jelas. Berikut analisis $5 \mathrm{~W}+1 \mathrm{H}$ :

1. What (apa) - faktor apa yang diperbaiki

Faktor yang diperbaiki adalah pengawasan lebih dalam terhadap pengendalian persediaan dan penjadwalan bahan baku impor. Hal ini sudah diketahui dengan adanya data bahan baku impor dan data pemesanan bahan baku impor dari data MRP.

2. Why (mengapa) - penyebab dari perbaikan yang akan dilakukan

Perbaikan dilakukan supaya pasokan bahan baku impor tepat waktu dan tepat jumlah sesuai kebutuhan produksi dan dapat menekan nilai inventory.

3. Where (di mana) - tempat melakukan peluang perbaikan

Peluang perbaikan dilakukan di bagian supply planning dengan dukungan dari seluruh tim pada supply planning dan departemen terkait yaitu produksi, gudang, dan logistik.

4. When (kapan) - batas waktu pelaksanaan peluang perbaikan

Penelitian untuk perbaikan dilakukan selama 4 bulan sebagai uji coba. Jika hasilnya memberikan dampak positif bagi perusahaan maka untuk selanjutnya dapat terus diterapkan di perusahaan.

5. Who (siapa) - yang melakukan peluang perbaikan

Perbaikan dilakukan oleh supply planning admin dengan melakukan keseluruhan penelitian ini yang dimulai dari identifikasi semua data yang berhubungan dengan bahan baku impor sampai mendapatkan hasil dari penelitian.

6. How (bagaimana) - bagaimana melakukan peluang perbaikan

Penelitian dalam melakuakan perbaikan ini dilakukan dengan metode pencarian heuristik. Setelah mendapatkan data baru sebagai indikator yang memperkuat pengawasan terhadap bahan baku impor, selanjutnya diterapkan di semua pemesanan bahan baku impor.

Selanjutnya, perhitungan safety stok berdasarkan persamaan (1) yang bersifat review untuk bahan baku impor kelas A adalah sebagai berikut:

1. Canola Oil

Mean demand

Std Dev

4.151.580,13

$\rightarrow$ Rata-rata konsumsi per tahun

Service level $60.154,10$

$\rightarrow$ Standar deviasi dari konsumsi

Service Factor $85 \%$

Safety stock

1,04

$\rightarrow$ Persentase nilai $Z$

$62.345,71$

$\rightarrow$ Tabel Z

$\rightarrow$ Service Factor $\times$ Std Dev

Karena pengaturan pengiriman dilakukan secara parsial maka safety stock diperhitungkan per minggu sehingga nilai dibagi 4 menjadi $15.586,43 \mathrm{~kg}$ per minggu. 
2. Onion Powder

Mean demand

Std Dev

267.242,92

$82.366,06$

Service level

Service Factor

Safety stock

$85 \%$

1,04

$85.366,93$ $\rightarrow$ Rata-rata konsumsi per tahun

$\rightarrow$ Standar deviasi dari konsumsi

$\rightarrow$ Persentase nilai $Z$

$\rightarrow$ Tabel Z

$\rightarrow$ Service Factor $\times$ Std Dev

Karena pengaturan pengiriman dilakukan secara parsial maka safety stock diperhitungkan per minggu sehingga nilai dibagi 4 menjadi $15.586,43 \mathrm{~kg}$ per minggu.

3. Garlic powder

Mean demand

Std Dev

$194.438,41$

$62.975,09$

Service level

Service Factor

Safety stock
$85 \%$

1,04

$65.269,49$ $\rightarrow$ Rata-rata konsumsi per tahun

$\rightarrow$ Standar deviasi dari konsumsi

$\rightarrow$ Persentase nilai $\mathrm{Z}$

$\rightarrow$ Tabel Z

$\rightarrow$ Service Factor $\times$ Std Dev

Karena pengaturan pengiriman dilakukan secara parsial maka safety stock diperhitungkan per minggu sehingga nilai dibagi 4 menjadi $16.317,37 \mathrm{~kg}$ per minggu.

\section{KESIMPULAN}

Berdasarkan hasil pengolahan data dan analisis yang telah dilakukan, maka dapat diambil kesimpulan sebagai berikut.

1. Klasifikasi 26 item bahan baku impor dengan analisis $A B C$ persediaan adalah:

a. kelas A terdiri atas 3 item bahan baku impor;

b. kelas B terdiri atas 6 item bahan baku impor; dan

c. kelas $\mathrm{C}$ terdiri atas 16 item bahan baku.

2. Penyebab ketidakefisienan stock dan value inventory adalah tidak dilakukannya pengendalian dan penjadwalan pasokan, setelah penelitian dan dilakukan rescheduling maka risiko shortage dapat dikurangi sebanyak $26 \%$, overstock dapat dikurangi sebesar $12 \%$, dan secara total keseluruhan value over value inventory dapat diturunkan sebanyak $23 \%$.

3. Efisiensi inventory dapat dilakukan dengan kontrol yang ketat pada pengendalian pasokan dan penjadwalan bahan baku impor khususnya kelas A yang diikuti kelas B dan C, dengan menerapkan rescheduling jadwal pengiriman dengan aplikasi waktu frozen horizon, sehingga bahan baku mendekati quantity kebutuhan dan efisiensi inventory dapat dicapai.

\section{REFERENSI}

[1] Indrajit, R.E. \& Djokopranoto, R., 2003. Manajemen Persediaan. Jakarta: Gramedia.

[2] Handoko, T.H., 1994. Dasar-Dasar Manajemen Produksi dan Operasi Edisi I. Yogyakarta: BPFE-Yogyakarta.

[3] Atmaja, H.K., 2012. Penggunaan Analisis ABC untuk Pengendalian Persediaan. FKM UI.

[4] Masruroh, N., 2012. Penerapan Metode Fixed Order Interval atau Fixed Order Quantity dalam Pengendalian Persediaan. Jurnal Teknik Industri, ISSN: 1979-911X.

[5] Biegel, J.E., 1992. Pengendalian Produksi suatu pendekatan Kuantitatif. Jakarta: Akademika Pressindo.

[6] Assauri, S., 2008. Manajemen Produksi (Edisi Revisi). Jakarta: Lembaga penerbit FE-UI.

[7] Tersine, R.J., 1994. Principles of Inventory and Materials Management, Fourth Edition. New Jersey: Prentice-Hall, Inc. Englewood Cliffs.

[8] Sulayman, et.al., 2013. Rancangan Sistem Perencanaan Produksi dan Pengendalian Persediaan dengan Mempertimbangkan Efisiensi Biaya Pada PT X. Jurnal Titra, 1(2).

[9] Gasper, V., 2005. Production Panning and Inventory Control. Jakarta: PT Gramedia Widiasarana Indonesia.

[10] Sutarman, 2003. Perencanaan persediaan bahan baku dengan model backorder. Infomatek, 5(3), pp.141-152. 